\title{
A Method to Evaluate the Suitability of Requirements Specifications for Offshore Projects
}

The success of an offshore application development project based on division of labor on the one hand heavily depends on the quality of the developed requirements specifications. On the other hand, even a poor quality of requirements specifications can possibly be compensated during the course of the offshore project. In this contribution, we present a method to evaluate the suitability of requirements specifications for an offshore project. For this purpose, we consider eight quality criteria and five potentially compensating factors. The application of the method is illustrated by a complex case study that has been conducted with an industry partner.

\section{DOI 10.1007/s12599-010-0106-8}

\section{The Authors}

Dr. Sven Overhage ( $\varangle)$
Dr. Oliver Skroch
Prof. Dr. Klaus Turowski
Business Informatics \& Systems
Engineering Chair
University of Augsburg
Universitätsstraße 16
86159 Augsburg
Germany

sven.overhage@wiwi.uni-augsburg.de, oliver.skroch@wiwi.uni-augsburg.de, klaus.turowski@wiwi.uni-augsburg.de

Received: 2009-08-01

Accepted: 2010-01-31

Accepted after one revision by the editors of the special focus.

Published online: 2010-04-28

This article is also available in German in print and via http://www. wirtschaftsinformatik.de: Overhage $S$, Skroch O, Turowski K (2010) Eine Methode zur Bewertung der Eignung von Anforderungsspezifikationen für Offshoring-Projekte. WIRTSCHAFTSINFORMATIK. doi: 10.1007/ s11576-010-0222-6.

(c) Gabler Verlag 2010

\section{Motivation}

Assigning the development and operation of information processing functions to external partners became a sustainable business model in 1963 at the lat- est, when the EDS company agreed with the Blue Cross health insurance to completely take over their IT (Dibbern et al. 2004, pp. 7 f). Contracting out parts of business application development to external service providers has become a standard planning alternative today. For some time, the offshoring approach outsourcing to low-wage areas that are envisaged to be far away and barely regulated ("off shore") - has been propagated in the course of globalization and has become the focus of considerations (Aspray et al. 2006, p. 6, 15; Kobitzsch et al. 2001, pp. 78 ff; Pryor and Keane 2004, pp. $11 \mathrm{ff})$.

On the contracting side, there primarily is the expectation of reducing costs through wage and price differentials between client and contractor areas. Aspray et al. (2006, pp. $6 \mathrm{f}$ ) argue that economic theory as well as anecdotal evidence show economic benefits for clients and contractors. On the other hand, additional costs resulting from offshoring parts of the business application development are emphasized (Dibbern et al. 2008). Overby (2003, p. 65), for example, estimates that up to ten percent of additional costs incur for the necessary improvement of development processes only.

Today, offshoring is seen as a global mega trend (Boos et al. 2005, pp. 6 f), and such approaches are now being pursued even for highly complex development projects. With the global allocation of development work to various stakeholders based on division of labor, the development task is directly subject to an interorganizational and cross-cultural context where implicit assumptions can hardly be made (Hofstede 1997; Vlaar et al.
2008, pp. 227 ff; Winkler et al. 2007, p. 96). Especially in such a context, necessary functions of an application system and required interfaces to other software components can only be explicitly specified through precise, intersubjectively unambiguous requirements specifications (Davis 1993). Therefore, requirements specifications constitute the substantive basis of the division of labor, become contractually agreed specifications of services (Gsell et al. 2008, pp. 26 ff; Overhage 2006, pp. 122 ff), and are therefore one of the most important factors for offshore projects (Overby 2003, p. 65; Sakthivel 2007, p. 70).

Although precise requirements specifications are crucial and their quality has great influence on the results of subcontracted steps of application development (Wehrmann and Gull 2006, p. 407 , pp. $413 \mathrm{f}$ ), it is observed in practice that they routinely remain unclear and thus may create significant difference of opinion in regard to the agreed scope of services (Heindl and Biffl 2006, p. 21; Pruß and Skroch 2008; Vlaar et al. 2008 , p. 235). For a decision on the offshoring of development steps, it is therefore essential to assess the suitability of requirements specifications in advance, e.g., based on criteria that have to be met. Despite the central importance of such an assessment, however, so far there have been hardly any efforts described to support this issue systematically and specifically with regard to offshore projects.

In this paper, we present a method to systematically and rationally assess the suitability of requirements specifications for the offshoring of development steps. The approach is characterized by 
Table 1 Process steps of application development (simplified)

\begin{tabular}{|c|c|c|c|c|c|}
\hline Step & Conception & Analysis & Design & Implementation & Acceptance \\
\hline Allocation & Onshore & Onshore & On-/Offshore & On-/Offshore & Onshore \\
\hline Starting point & Business goals & $\begin{array}{l}\text { Feasible } \\
\text { targets }\end{array}$ & $\begin{array}{l}\text { Requirements } \\
\text { specification }\end{array}$ & Design & $\begin{array}{l}\mathrm{Rfa}^{\mathrm{a}} \text { of the } \\
\text { solution }\end{array}$ \\
\hline Core activity & $\begin{array}{l}\text { Requirements } \\
\text { analysis }\end{array}$ & $\begin{array}{l}\text { Requirements } \\
\text { analysis }\end{array}$ & $\begin{array}{l}\text { Architecture, } \\
\text { planning }\end{array}$ & $\begin{array}{l}\text { Programming, } \\
\text { integration }\end{array}$ & Testing \\
\hline Core deliverable & $\begin{array}{l}\text { High-level } \\
\text { requirements, } \\
\text { feasibility }\end{array}$ & $\begin{array}{l}\text { Detailed } \\
\text { requirements }\end{array}$ & $\begin{array}{l}\text { Design } \\
\text { documents, } \\
\text { detailed plans }\end{array}$ & $\begin{array}{l}\text { Completed } \\
\text { application } \\
\text { system }\end{array}$ & List of defects \\
\hline
\end{tabular}

${ }^{\mathrm{a}} \mathrm{Rfa}$ : ready for acceptance

two main features. First, the evaluation can be carried out without reconsulting users from the departments - who represent the requirements as regards content - for further clarification. In practice, such an approach would cause ongoing difficulties because of the users' limited availability and their limited willingness to discuss already given requirements again. Second, the approach's assessment also includes compensation opportunities, which makes it possible to (totally or partially) balance out specification deficiencies in a particular offshore project - these then constitute critical success factors for the offshore project to be carried out. For the preparation of appropriate sourcing activities, the presented approach not only makes it possible to assess a specification in terms of high or low quality. Additionally, it becomes possible to highlight compensating options for the responsible decision makers.

In developing the evaluation method, we followed the design-oriented approach of business and information systems engineering (BISE), specifically the design science method (Hevner et al. 2004). Apart from the theoretical foundation and iterative improvement, the latter also includes an explicit validation, which was primarily carried out in the context of a large case study. Here, the developed method was used in a large development project for custom software, providing decision support in the planning of the offshore parts of the project. The further presentation of the developed evaluation method is based on the design science cycle which differentiates between the formulation of the problem, the solution concept, the realization of the solution, and its validation as key steps (Takeda et al. 1990, p. 43).

Section 2 describes the theoretical background and related approaches for the assessment of requirements specifications in order to highlight the existing research gap. Section 3 presents the conceptual basis of the evaluation method before it is presented in detail in Section 4. Section 5 includes a reflection of the performed case study as well as a reception of the results obtained. At the end of the contribution we discuss implications for science and practice as well as remaining research questions.

\section{Background and Related Approaches}

\subsection{Outsourcing, Offshoring, and Application Development Based on the Division of Labor}

The theoretical foundations of outsourcing have already been defined by Coase (Coase 1937, pp. $386 \mathrm{ff}$ ) with his question about the limits of a firm, which among others served as a foundation for transaction cost economics. Along the value creation chain cost comparisons must determine whether subtasks are carried out internally or externally. Erber and SayedAhmed (2005, p. 100) distinguish offshoring, inshoring, nearshoring, and onshore for the external processing. From the client's perspective, offshoring refers to the relocation of subtasks in areas far outside the national borders, while inshoring describes the same phenomenon from the contractor's perspective. In the case of nearshoring, client and contractor are located in close geographical proximity. Onshore means that both parties are located in the same country.

Processes based on the division of labor can also be realized for business application development, which today generally is carried out starting from conception and analysis to cover design and finally also implementation and acceptance. The development can include iterative and distributed elements, and can be accompanied by various quality assurance measures, as described e.g. by Hansen and Neumann (2009, pp. 364 ff).

Table 1 summarizes these typical, successive steps of application development each with their respective starting points, core activities, and results of the individual subtasks. At the end of each process step, the results should be documented in order to be used in subsequent steps. To emphasize the decision situation supported by the evaluation method, additional assumptions are made about the preconceived allocation options of individual development steps. Here, a decision on an offshore realization is envisaged for the design and/or implementation. Similar scenarios are also used by e.g. Boos et al. (2005, p. 25), Cusick and Prasad (2006, pp. 22 f), or King and Torkzadeh (2008, pp. 209 ff) for the discussion of offshoring approaches.

\subsection{The Importance of Requirements Specifications for Offshoring}

In their case study, Vlaar et al. (2008, pp. $227 \mathrm{ff})$ describe in detail the misunderstandings that may occur between a client's team that is responsible for the requirements analysis and the design, and an implementing team of the offshore contractor. Vlaar et al. (2008, p. 235) summarize that "offshore team members could only develop literal understanding of the requirements" and thus point out how difficult it is to achieve an intersubjectively shared understanding of requirements in offshore projects. They explain that problems particularly result from "knowledge and experience asymmetries" as well as from "complex, novel and instable tasks and requirements" (Vlaar et al. 2008, p. 242). From 
their argument that "requirements development is a fundamentally humanoriented and socially mediated process in which understandings are socially constructed" (Vlaar et al. 2008, p. 239) it becomes clear that in the case of the offshoring of development steps additional difficulties in the already complex process of specifying requirements occur.

"The ability to write clear specifications" is consequentially identified by Overby (2003, p. 65) as a key factor in the outsourcing of development tasks. Moreover, Wehrmann and Gull (2006, p. 407, pp. $413 \mathrm{f}$ ) argue that uncertainties in the requirements have a strongly negative impact on offshoring. In a study of distributed development projects Heindl and Biffl (2006, p. 21) show that the highest risks result from "misinterpretation and unclear rationale of requirements". The quality of requirements specifications is therefore an essential risk factor for offshore projects (Sakthivel 2007, p. 70).

\subsection{Evaluation Approaches for Requirements Specifications}

Although the assessment of the suitability of requirements specifications thus has a central relevance for the decision on offshoring development steps, few methods have been described by now which systematically support this task. In practice, the quality of large specification documents is often ensured ad hoc, little systematically, and with high human efforts. Most theoretical work, however, is devoted to the creation of formally correct specifications which can hardly be applied in practice. Scheffczyk et al. (2004, pp. $2 \mathrm{ff})$ describe a commercially used method, which seeks to master this balancing act. Regarding the content, however, a substantive assurance of the requirements' consistency cannot be found here.

From the realm of experiences in a multinational conglomerate, Berenbach and Borotto (2006, p. 448) describe seven quality metrics used in UML (Unified Modeling Language) modeling. However, these again only cover the formal correctness of requirements and state nothing about their suitability as regards content. While in this approach every specification needs to meet the previously defined formal requirements, such a view is not sufficient for supporting a decision on an offshore project. In fact, a requirements specification in the terms of the approach by Berenbach and Borotto (2006, p. 446) could be complete even though requirements are missing (e.g., because they have not been modeled at all). For a comprehensive statement on quality, this relatively simple, formal verification therefore has to be supplemented by a more difficult validation as regards content.

Krogstie (1998, pp. 86 ff) proposes an integrated framework for the quality assessment of requirements specifications, building upon the author's previous work and referring to the semiotic model by Morris (1970, pp. 13 ff). The author shows that some of the classically discussed quality attributes, such as uniqueness of a specification, involve the dilemma that they can only be determined when the domain to be modeled is intersubjectively understood in a clear way already in advance (Krogstie 1998 , p. 88 , pp. 90 f). This understanding, however, is to be attained through the specification process that otherwise would only be of documentary significance. In this way the quality framework addresses many quality attributes, but it remains too abstract for the actual application.

Wehrmann and Gull (2006, p. 407) suggest a complex cost estimation approach for the application development in offshore projects. They note that focusing on wage differences provokes miscalculation and that cost advantages rather depend on high-quality product requirements. In contrast, uncertainties of the requirements have a highly negative impact on the expected cost advantage, which cannot be further quantified with their method however. Dibbern et al. (2008, pp. $336 \mathrm{ff})$ provide a model to explain costs in offshore projects. While they classify specification costs as crucial in the way that they should be included as one of five exogenous model variables, an evaluation of the suitability of a requirements specification for an offshore project is again not supported by their explanatory model.

Taking the mentioned works into account, in the next sections we describe, deploy, and validate a method which makes it possible to systematically verify the quality of documented requirements and their suitability for offshore development steps. The method intends to close the existing research gap and contribute to ensure that decisions about offshore projects can be based on a more comprehensive foundation in practice.

\section{Conceptual Basics}

Requirements that are documented in a specification form the basis of and constitute the drivers for further development steps. They describe the functionality to be provided by an application system under certain conditions in the most precise and implementation-independent form based on the "externally" observable behavior of the application. Thus, they indicate what an application system performs without dwelling on how this is achieved (Liskov and Berzins 1986).

A declining specification quality usually leads to a higher interpretability for a third party as regards the content of the existing requirements. Hereby, direct implementation risks for the offshoring of later development steps are generated (Fig. 1) which can be specifically balanced out by compensating factors. The lower the quality of the requirements specification, the higher is the risk that the necessary compensation cannot be afforded in subsequent development steps so that the quality of the implemented application system is impaired.

Thus, in addition to the specification quality we also have to consider possible compensating factors through which existing specification gaps can possibly be balanced out when assessing the suitability of a requirements specification for an offshore project. Through such a sophisticated evaluation an additional scope for action results when deciding on an offshore project, which bears importance for practice. There, we can assume on the one hand just for economic reasons that complex requirements specifications

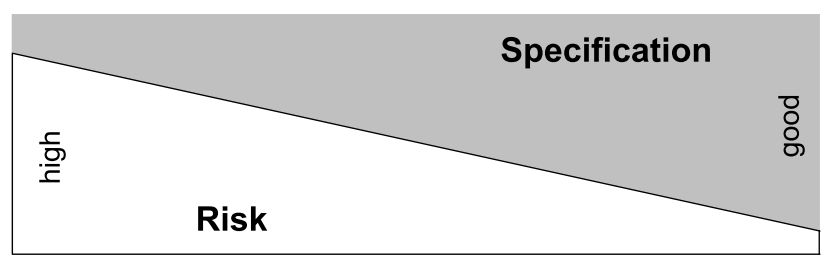

Fig. 1 Relation between the specification quality and implementation risks 
cannot be arbitrarily improved after a potentially negative assessment. On the other hand, a development project has to deliver on its scope in the given time whilst adhering to budget constraints. Therefore, the method for the evaluation of requirements specifications proposed in this paper also explores alternative measures which may achieve a compensation of specification deficiencies that no longer can be overcome economically in an offshore project. Decision makers then can assess whether and how the compensation effort of an offshore project makes sense in a situational context despite existing specification deficits. However, the actions recommended as compensating factors then constitute critical success factors.

\subsection{Specification Quality}

To assess how well a requirements specification is suited for the outsourcing of development work we generally have to consider different quality criteria. After evaluating the relevant literature, we used eight criteria for the evaluation method presented in this paper. These criteria were already used by the authors to evaluate specification approaches for development scenarios based on division of labor (Overhage 2006; Overhage and Thomas 2005). Overall, the following quality criteria of requirements specifications are to be assessed (Becker et al. 1995, pp. 437 ff; Brown 2000, pp. 102 f; D'Souza and Wills 1999, p. 321; Davis 1993, pp. 181 f; Hall 1990, pp. 16 f; IEEE 1998, pp. 4 ff; Liskov and Berzins 1986, p. 3; Schienmann 1997, p. 26):

- $q_{1}$ consistency. The specification is supposed to clarify the relations between their individual components and to avoid contradictions between different parts of the specification in particular.

- $q_{2}$ adequacy. The outside view of the software should be described with reasonable efforts and at the same time in the highest possible precision - in particular, in a way that design and implementation tasks can be carried out with the specifications.

- $q_{3}$ feasibility. The specification should make use of notations established in practice that can be used effectively by all parties involved in the development.

- $q_{4}$ flexibility. The specification should have a uniform and modular structure so that requirements can be changed locally, if necessary.
- $q_{5}$ standardization. The specification should comply with mandatory, explicitly documented standards and guidelines concerning form and content.

- $q_{6}$ comprehensibility. Both the machine interpretability and the readability for people should be given. This means that on the one hand formal notations with precise syntax and semantics should be used, which on the other hand should also be presented in an easily understandable form with additional comments.

- $q_{7}$ completeness. All features of the application should be set in a way that makes it possible to conduct further development work on this basis. Completeness is required relatively, for example in terms of support for each specified task.

- $q_{8}$ neutrality. The specification should be independent of technologies and methods for the further development (design, programming, etc.).

To assess the above mentioned quality criteria in a decision situation they must be further operationalized and supplemented by concretely measurable dimensions. This is dependent on the context, such as for example on the specification methods. Therefore, it generally has to be performed according to situational peculiarities. As part of the case study discussed later, this contribution shows how the criteria were actually used there. For more information on the concrete terms of the above criteria the reader is referred to the relevant literature (IEEE 1998, pp. 4 ff; van Lamsweerde 2009, pp. $87 \mathrm{ff}, 187 \mathrm{ff}$ ).

\subsection{Compensation Factors}

Existing specification deficits may be compensated or at least controlled by specific measures during the offshoring project. In order to determine which compensating factors can be used specifically in such projects, we evaluated reviews and case studies on offshoring, outsourcing, and distributed application development. The analyzed works describe options for action that allowed the compensation of specification deficits completely or in parts. The relevant factors include the respective offshore partner's characteristics and possibilities of cooperation, but also the contractual design of the project.

The options for action are summarized in five compensating factors for decision makers in offshore projects in Table 2. References that discuss all the collected compensating factors are highlighted in bold. In the context of each project therefore an investigation is necessary whether a situational compensation for specification deficits seems attainable through the observance of these compensating factors when selecting an offshore partner. The following factors are to be analyzed (Bhat et al. 2006, p. 43; Boos et al. 2005, p. 42 f; Corriveau 2007, p. 27; Davenport 2004, pp. 3 f; Gefen et al. 2008, p. 533; Heeks et al. 2001, pp. 58 f; Kojima and Kojima 2007, pp. 71 ff; Lacity and Willcocks 2003, p. 118; MacGregor et al. 2005, p. 2 f; Moczadlo 2002, pp. 7 f; Nevo et al. 2006, p. 5; Remus and Wiener 2009, p. 13; Sakthivel 2007, p. 70; Setamanit and Raffo 2008, p. 325; Siakas et al. 2006, pp. 175 ff; Steimle 2007, pp. 115 f; Tsuji et al. 2007, p. 121; Vlaar et al. 2008, p. 229; Wada et al. 2007, p. 131; Winkler et al. 2007, p. 96):

- $e_{1}$ domain knowledge. To what extent does the offshore partner have indepth experience with similar requirements in general, and thus already possesses an implicit understanding of the application domain?

- $e_{2}$ communication, language, and culture. How easy or difficult is the operational communication between the offshore partners, in particular directly and personally?

- $e_{3}$ learning relationship. How mutually familiar are the respective partners with the people, the business, and the processes of the counterparts?

- $e_{4}$ reliability. What is the strategic interest or business model of the offshore partners? How qualified and motivated are the operational teams?

- $e_{5}$ contracting. How does the contract support detailing, clarification, and possible amendment of guaranteed characteristics in the course of the development project?

In most references, factor $e_{2}$ is not mentioned as a single factor. However, it makes sense to consider communication, language, and culture in context as is done here (Christiansen 2007, p. 25; Hofstede 1997).

\section{Design of the Evaluation Method}

The quality criteria and compensating factors form the basis for the rational evaluation method, i.e. a method that is 
Table 2 Compilation of compensating factors in offshore projects

\begin{tabular}{|c|c|c|c|c|c|}
\hline Compensation & $\begin{array}{l}\text { Domain } \\
\text { knowledge } \\
e_{1}\end{array}$ & $\begin{array}{l}\text { Communication, } \\
\text { language and } \\
\text { culture } \\
e_{2}\end{array}$ & $\begin{array}{l}\text { Learning } \\
\text { relationship } \\
\mathrm{e}^{3}\end{array}$ & $\begin{array}{l}\text { Reliability } \\
e_{4}\end{array}$ & $\begin{array}{l}\text { Contracting } \\
e_{5}\end{array}$ \\
\hline Bhat et al. (2006) & & $x$ & $x$ & $x$ & \\
\hline Boos et al. (2005) & $x$ & $x$ & $x$ & $x$ & $x$ \\
\hline Corriveau (2007) & & & & & $x$ \\
\hline Davenport (2004) & $x$ & $\times$ & & & \\
\hline Gefen et al. (2008) & $x$ & & $x$ & & $x$ \\
\hline Heeks et al. (2001) & $x$ & $x$ & $x$ & & \\
\hline Kojima and Kojima (2007) & $x$ & $x$ & $x$ & $x$ & $x$ \\
\hline Lacity and Willcocks (2003) & & & & & $\times$ \\
\hline MacGregor et al. (2005) & & $x$ & & & \\
\hline Moczadlo (2002) & & $x$ & $x$ & & \\
\hline Nevo et al. (2006) & $x$ & $x$ & & $x$ & \\
\hline Remus and Wiener (2009) & $x$ & $x$ & $x$ & $x$ & $x$ \\
\hline Sakthivel (2007) & & & $\times$ & & $\times$ \\
\hline Setamanit and Raffo (2008) & & $x$ & $\times$ & & \\
\hline Siakas et al. (2006) & & & $x$ & $x$ & \\
\hline Steimle (2007) & & $x$ & $x$ & $x$ & $x$ \\
\hline Tsuji et al. (2007) & $x$ & $x$ & $x$ & $x$ & $x$ \\
\hline Vlaar et al. (2008) & $x$ & $x$ & $x$ & & \\
\hline Wada et al. (2007) & $x$ & $x$ & $x$ & $x$ & $x$ \\
\hline Winkler et al. (2007) & & $x$ & $x$ & $x$ & \\
\hline
\end{tabular}

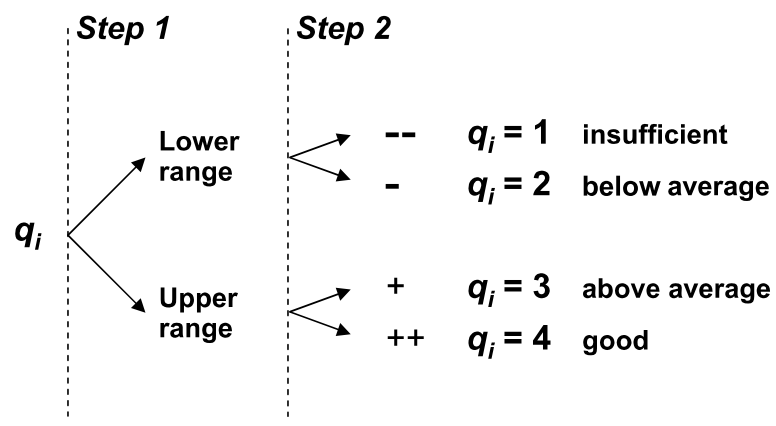

Scale (aggregated)

$[1,00 \ldots 1,75)$

$[1,75 \ldots 2,50)$

$[2,50 \ldots 3,25)$

[ $3,25 \ldots 4,00$ ] transparent for the decision maker and is well founded in relation to the approach. As a key element we employ the cost-utility analysis approach that was introduced by Zangemeister (1976) for the multidimensional assessment and selection of project alternatives, and represents a proven method for decision making today (Klein and Scholl 2004, p. 87).

\subsection{Procedure for Determining the Specification Quality}

To determine the quality of a requirements specification we classify this specification against each of the eight criteria presented $q_{i}(i=1, \ldots, 8)$ on a fourstage rating scale. On the scale, higher values express better suitability (Fig. 2). Depending on the specific project and the preferences of decision makers, each quality criterion can be optionally fitted with a weight $g_{i}(i=1, \ldots, 8)$. The overall assessment $Q$ of the specification is then calculated by

$Q=\frac{1}{8} \sum_{i=1}^{8} g_{i} q_{i} \quad$ with $q_{i} \in\{1,2,3,4\}$.

Without an explicit definition of weights, all criteria are rated with an equal weight during the evaluation, thus $g_{i}=1 \forall i$ holds. In case of an explicit weighting an appropriate normalization of $g_{i}$ can be recommended, for example such that $\sum_{i=1}^{8} g(i)=8$.

The evaluation of the specification quality for each $q_{i}$ is carried out individually and qualitatively by classification from the decision makers. Here, it is first determined whether the specification quality is in the upper ("above average or better") or lower ("below average or worse") range. Then the classification is refined and it is determined whether the specification within the upper range is thoroughly rated as "good" or only as "above average". Accordingly, one proceeds within the lower range, so that an overall range between 1 (worst) and 4 (best) results (Fig. 2).

Before the rating can be carried out, the specifications initially have to be analyzed by experts. The variety of the quality criteria to be assessed on the one hand intends to ensure the broadest possible analysis of specification documents. On the other hand, the evaluation generates 
Table 3 Graphical representation of expected compensation effects (example)

\begin{tabular}{|c|c|c|c|c|c|}
\hline \multirow[t]{2}{*}{ Quality criteria } & \multicolumn{5}{|c|}{ Success factor } \\
\hline & $e_{1}$ & $e_{2}$ & $e_{3}$ & $e_{4}$ & $e_{5}$ \\
\hline$q_{1}$ & $\hookleftarrow$ & $\hookleftarrow$ & & & \\
\hline$q_{2}$ & & & $\hookleftarrow$ & $\hookleftarrow$ & $\hookleftarrow$ \\
\hline$q_{3}$ & & $\hookleftarrow$ & & & \\
\hline$q_{4}$ & $\hookleftarrow$ & & & & \\
\hline$q_{5}$ & $\hookleftarrow$ & $\longleftarrow$ & & & \\
\hline$q_{6}$ & & & $\hookleftarrow$ & & $\hookleftarrow$ \\
\hline$q_{7}$ & $\hookleftarrow$ & & & & \\
\hline$q_{8}$ & & $\longleftarrow$ & & & \\
\hline
\end{tabular}

additional efforts that should be limited by appropriate analytical techniques (e.g. sampling or clustering). One possible approach for this purpose is described later using the example case. The overall assessment which results from the application of the value analysis describes the quality of the specification.

\subsection{Procedure for Determining the Compensation Options}

If specification deficiencies have been identified, we individually and qualitatively analyze for each of the impaired quality criteria $q_{i}(i=1, \ldots, 8)$ whether a balancing effect $k_{i j} \in\{0 ; 1\}$ can be expected in the project situation through the previously described compensating factors $e_{j}(j=1, \ldots, 5),\left(k_{i j}=0\right.$ for no, $k_{i j}=1$ for yes). The balancing effects of the compensating factors in relation to the quality criteria is shown by the compensation matrix

$$
\begin{aligned}
& K=\left(k_{i j}\right)=\left(\begin{array}{ccc}
k_{11} & \ldots & k_{15} \\
\vdots & \ddots & \vdots \\
k_{81} & \ldots & k_{85}
\end{array}\right) \\
& \text { with } i=1, \ldots, 8, j=1, \ldots, 5 \\
& \text { and } k_{i j} \in\{1,0\} .
\end{aligned}
$$

The vertical compensation vectors $\vec{k}_{i 1}^{V}=\left(k_{11}, k_{21}, k_{31}, \ldots, k_{81}\right)$ to $\vec{k}_{i 5}^{V}=$ $\left(k_{15}, k_{25}, k_{35}, \ldots, k_{85}\right)$ indicate which quality criteria are influenced by one compensating factor. The horizontal compensation vectors $\vec{k}_{1 j}^{H}=$ $\left(k_{11}, k_{12}, k_{13}, k_{14}, k_{15}\right)$ to $\vec{k}_{8 j}^{H}=\left(k_{81}, k_{82}\right.$, $k_{83}, k_{84}, k_{85}$ ) show what factors effect a compensation for one quality criterion.

Starting point for the compensation effort is the search for factors that at least partly enable compensating quality deficiencies in the requirements specification. The proposed analysis therefore focuses on the determination of the vertical compensation vectors. It pursues the question of what compensating effect can be expected from the various factors in the specific project situation (Table 3 ). In the style of the min-max principle, according to which the maximum negative consequences are to be minimized, we aim at a compensation especially for the lowest-rated quality criteria of a requirements specification.

\subsection{Further Refinement of the Evaluation}

In the proposed approach for assessing requirements specifications, a lower quality measure implies a lower suitability of a requirements specification for the offshoring of development steps. It is also assumed that the suitability of a deficiency-afflicted specification is increased if effective compensating factors can be identified. For the assessment of the suitability we can supplement the condensed measure, which has been determined by the cost-utility analysis, by further analyses. Given the ordinal nature of the four-step scale, the measure allows the classification of the specification quality (Fig. 2). However, it is not possible to make absolute statements and refer to specifications that are e.g. "twice as good" in comparison to others. Furthermore, the condensed measure alone implies that poor ratings of a quality criterion may be balanced out by good ratings of another one.

The further differentiation of the analysis may, for example, be performed using so called radar charts (Bensberg 2008), where in particular the possible compensating factors are to be integrated. Moreover, the assessment of individual criteria and their weights can be varied e.g. in the course of a sensitivity analysis. This allows an analysis to what extent the assessment depends on the suitability of the input variables, and thus how stable the results are. For the evaluation of the results of a cost-utility analysis as well as for supporting software tools, literature provides further reference (Bensberg 2008; Klein and Scholl 2004, p. 47).

\section{Evaluation}

The proposed evaluation method has been used in a case study that was hosted at a leading corporation in the automotive business. The suitability of extensive requirements specifications (including around 700 UML use cases) for the offshoring of further development steps had to be examined for one large development project. The purpose of the project was the development of an individually specified, complex and businesscritical application system for the support and automation of the group's global sales processes. The application system should, among other things, provide the customized configuration of industrially produced technical capital goods and high quality consumer products for the global market. In the large development project the budgeted number of days of work for the preparation of requirements specifications by the client's internal employees alone amounted to a figure in the middle four digits. At the beginning of the case study, the specification of the requirements had been completed. The further project plan was to transfer large parts of the design and implementation to an offshore partner. The assessment of the requirements specifications began after the project management had approved the use of the presented evaluation method. The approach was conducted by an evaluation team including the authors of this contribution and representatives of the project leaders. 
Table 4 Identified compensating factors and balancing effects

\begin{tabular}{|c|c|c|c|c|c|}
\hline \multirow{3}{*}{$\begin{array}{l}\text { Quality criteria } \\
\text { that has been } \\
\text { assessed as low }\end{array}$} & \multicolumn{5}{|c|}{ Success factor } \\
\hline & $\underline{e_{1}}$ & $\underline{e_{2}}$ & $\underline{e_{3}}$ & $\underline{e_{4}}$ & $e_{5}$ \\
\hline & $\begin{array}{l}\text { Domain } \\
\text { knowledge }\end{array}$ & $\begin{array}{l}\text { Communication, } \\
\text { language and } \\
\text { culture }\end{array}$ & $\begin{array}{l}\text { Learning } \\
\text { relation- } \\
\text { ship }\end{array}$ & Reliability & Contracting \\
\hline$q_{1}$ consistent & & $\hookleftarrow$ & $\hookleftarrow$ & & \\
\hline$q_{2}$ adequate & $\hookleftarrow$ & $\hookleftarrow$ & $\hookleftarrow$ & $\hookleftarrow$ & $\hookleftarrow$ \\
\hline$q_{4}$ flexible & & $\hookleftarrow$ & $\hookleftarrow$ & $\hookleftarrow$ & $\hookleftarrow$ \\
\hline
\end{tabular}

\subsection{Determination of the Specification Quality}

To determine the $q_{i}$, in a first step all cross relations between the parts of the specification were investigated for inconsistencies, contradictions, gaps, redundancies, lack of specification parts, and missing or incorrect identifiers. In a second step this was followed by a detailed examination of the requirements specifications' key parts which had been identified as "central" by the contracting body. For cost reasons, this investigation was partially restricted to a representative part of the specifications using a Pareto analysis (also known as "ABC analysis"). To implement the Pareto analysis, the previously analyzed cross relations were evaluated to draw conclusions about the relationship between the various parts of the specification. The part of the requirements specification classified as representative included, among others, 22 percent of the "central" use cases.

The evaluation of the specification parts was initially carried out by a verification against internal rules of the client and - where applicable - against formal rules, such as those of the UML. In addition, a validation was carried out by determining the requirements details that were missing to unequivocally work out a design. Any scope for discretionary interpretation that could not be removed by the requirements specifications was considered as a deficit here. The results formed the basis for the determination of $q_{i}$ through a qualitative, consensusbased classification on the scale (Fig. 2) by the evaluation team. Starting with the lowest-rated criteria the following assessments resulted (described in a very shortened way):

- $q_{1}$ consistency: 1 (--). A higher-level specification structure to explain the relations between parts of the specification was not available. The structure of the whole system was not sufficiently clear.
- $q_{2}$ adequacy: 1 (- -). Due to the lack of precision of most of the requirements it was not possible to create a design of the application without additional elicitation.

- $q_{4}$ flexibility: 1 (- -). The specification parts were heavily dependent on one another; these dependencies were not well described.

- $q_{6}$ comprehensibility: 2 (-). Large parts of the requirements specification were modeled in a semi-formal specification language (UML). However, the reference to complementary natural language parts of the specification remained blurred.

- $q_{7}$ completeness: 2 (-). It was noted that specification parts that are relevant for the further development were described only incompletely or as a placeholders.

- $q_{3}$ feasibility: $3(+)$. The notations used in the analyzed parts of the specification are commonly used in practice and were directly applicable. Some techniques, however, were specific to the client.

- $q_{5}$ standardization: $3(+)$. In general, the explicit and implicit violations of standards and guidelines were low.

- $q_{8}$ neutrality: $4(++)$. The specification was described independently of technologies and methods for further development.

The investigation of the requirements specification revealed a total calculative value of 2.125 using (1), and thus was below the average rating of the scale (Fig. 2). For three of the eight quality criteria, the specification was classified as inadequate.

\subsection{Determination of the Compensation Possibilities and Options for Action}

To assess the suitability of the requirements specification for the offshoring of further development steps more comprehensively, possible compensating factors for the identified specification deficiencies were examined and discussed.
By consensus, the evaluation team determined for each compensating factor whether this factor can be expected to have a balancing effect, particularly on the characteristics classified as inadequate in this specific development situation (Table 4).

During the analysis, the following vertical compensation vectors were determined based on the observations and recommendations (simplified description):

- $e_{1}$ domain knowledge: $\vec{k}_{i 1}^{V}=\left(\mathbf{0}, \mathbf{1}, k_{31}\right.$, $\left.\mathbf{0}, k_{51}, k_{61}, k_{71}, k_{81}\right)$. The unclear overall structure of the specification can hardly be compensated by a good general understanding of the application domain. However, development partners with better domain knowledge can render single interpretable specification parts more precise, with relatively low risk. If specification parts are not designed for changeability in advance, they can hardly be adjusted by good domain knowledge alone.

- $e_{2}$ communication, language and culture: $\vec{k}_{i 2}^{V}=\left(1,1, k_{32}, 1, k_{52}, k_{62}, k_{72}\right.$, $k_{82}$ ). The explicit information about dependencies between parts of the specification should be supported by good communication. A common language and smooth operational communication are among the basic requirements for the further use of specifications with substantive deficiencies. In the case of specifications that are difficult or laborious to change, the solution identification for necessary modifications is simplified if the conflict cultures of the involved partners are compatible.

- $e_{3}$ learning relationship: $\vec{k}_{i 3}^{V}=(\mathbf{1}, \mathbf{1}$, $\left.k_{33}, \mathbf{1}, k_{53}, k_{63}, k_{73}, k_{83}\right)$. Existing knowledge of the business context through experiences from earlier collaborations between the involved parties facilitates problem solving for insufficiently concerted specification parts. The experience curve (learning relationship) simplifies the clarification of inaccurately specified 


\section{Abstract \\ Sven Overhage, Oliver Skroch, Klaus Turowski \\ A Method to Evaluate the Suitability of Requirements Specifications for Offshore Projects}

Today, even the development of business information systems is subject to the global offshoring trend. With the division of development work in an interorganizational and intercultural context, requirements specifications become the central means to communicate the development scope as explicitly as possible. The suitability of requirements specifications hence often is mission critical in offshore projects. To assess their suitability, we first present eight quality criteria for requirements specifications. We then discuss five critical compensating factors that may potentially balance out an insufficient specification quality during the offshore project. On this basis, we describe a method to rationally evaluate the suitability of requirements specifications for instantiating an offshore project. We illustrate the application of the method by elaborating on a large case study that has been conducted with an industry partner. The results achieved by applying our method were confirmed during the further course of the actual project.

Keywords: Application development, Requirements specification, Evaluation, Offshoring requirements. If partners are already familiar with mutual peculiarities and implications, even specifications that require high efforts for changing may be adapted with relative efficiency.

- $e_{4}$ reliability: $\vec{k}_{i 4}^{V}=\left(\mathbf{0}, \mathbf{1}, k_{34}, \mathbf{1}, k_{54}\right.$, $\left.k_{64}, k_{74}, k_{84}\right)$. Operational collaboration and strategic ties between the partners have little influence on the degree of coordination between specification parts. A high degree of reliability between the partners, however, makes it possible to better adjust inaccuracies in the requirements specification. In the case of a strategically committed management and an operationally reliable interaction between the development team members, changes to poorly modifiable specifications become more feasible.

- $e_{5}$ contracting: $\vec{k}_{i 5}^{V}=\left(\mathbf{0}, \mathbf{1}, k_{35}, \mathbf{1}, k_{55}\right.$, $\left.k_{65}, k_{75}, k_{85}\right)$. It does not seem plausible that specification parts should be better coordinated as a result of a flexible contract. However, the appropriate and flexible contract design is a precondition of being prepared for dealing with imprecise or unstable specifications and of effectively handling such situations externally. Flexible contracts can show possible solutions especially for those specifications that can only be modified with high expense.

In determining the compensation vectors particularly the possible balancing effects for the mostly affected quality criteria were examined, following the minmax principle. The analysis yielded an overall critical assessment of the suitability of the requirements specification for an offshoring of later development stages. To support decisions in favor of an offshore project, it was recommended to pay attention to the feasibility of the above described compensating factors when selecting partners and designing the project.

\subsection{Reception of the Results}

The client decided to implement an offshore project, waived a targeted implementation of compensatory measures but, given the evaluation results, limited the offshoring rate to a maximum of 40 percent of the project. After some time, we were able to analyze the project's progress and survey the client on the project results as well as on his assessment of the evaluation method during a retrospective interview.
The part of the project that has been conducted offshore was referred to as problematic. About 25 percent of the developed functionality had to be redeveloped completely; another 25 to 50 percent had to be partially revised. Overall, less than half of the offshore developments remained without rework. One reason given was the missing familiarity of the contractor with the individual peculiarities on the client side. Since neither in-depth knowledge of the application domain existed nor common experience from previous projects was available, the contractor could only compensate existing specification deficits at great expense. The unclear contract design in terms of compensation for deficits also led to discussions about who should bear the responsibility for problems in dealing with requirements specifications.

The offshore quota in the correction of defects and in change requests was reduced to zero in the later project. The entire offshore rate for the whole project finally was below 10 percent. The client estimated an unspecific "offshoring advantage" of only 10-15 percent on the bottom line. The client further stated that offshoring on the basis of poor requirements specifications works with largely standardized and generally known features and processes at best - but is badly suited for the implementation of individual and highly specific features as in the examined project. The method we used to evaluate the requirements specifications, and our analyzed compensation factors, were generally appraised by the client as "all together correct and relevant". The evaluation results and predictions could also be verified in detail by the actual course of the project, specifically through analyzing the issues that occurred as a consequence of neglecting the compensation measures. These concrete results from the evaluation method and the compensation recommendations were assertively confirmed as correct by the client also in the retrospective interview.

\section{Conclusion}

With the growing importance of offshoring as a decision option even for highly complex application development projects, the quality of requirements specifications has evolved to a central determinant. In this contribution we therefore described a method to evaluate 
the quality of requirements specifications systematically, comprehensively, with regard to several criteria, and in a rational process. In addition, compensating factors were included into the analysis to achieve a better control or even a rectification of specification deficits during the course of the project. The evaluation method does not require a renewed involvement of the user. In the case study, the assessment also accounted for only about four percent of the total expense which the client had estimated for the design and implementation on the basis of a function point analysis.

The presented research results have implications for both science and practice. For practice, the developed approach provides an immediately deployable, efficient way to constitute a better foundation for planning decisions for an offshoring project depending on the quality of available requirements documents. From a scientific point of view, the presented approach closed the research gap concerning decision support approaches for the planning of offshore projects for application development. To achieve a more comprehensive decision support in the planning of offshore projects, we particularly have to research further influencing factors. The method described in this paper presents a first step which was developed in terms of a design science approach and which has been iteratively improved. We focused on the quality of requirements specifications and specific compensating factors with a balancing effect on specification deficits.

The presented method itself is subject to further research to be carried out in further iterations of the design science cycle. On the one hand, focus is on the development of an algorithmic process to systematically derive the weights of the single quality criteria during the assessment based on the preferences of decision makers. The Analytic Hierarchy Process (AHP) serves as the basis for this purpose. On the other hand, we plan to develop so called best practices and guidelines for the application of the presented method through further case studies in collaboration with practice partners. In this way, we intend to further improve the desired offshore decision support.

\section{References}

Aspray W, Mayadas F, Vardi MY (eds) (2006) Globalization and offshoring of software: a report of the ACM job migration task force. The executive summary, findings, and overview of a comprehensive ACM report on the offshoring of software worldwide. ACM, New York

Becker J, Rosemann M, Schütte R (1995) Grundsätze ordnungsgemäßer Modellierung. WIRTSCHAFTSINFORMATIK 37(5): 435-445

Bensberg F (2008) Nutzwertanalyse. In: Kurbel K, Becker J, Gronau N, Sinz E, Suhl L (eds) Enzyklopädie der Wirtschaftsinformatik - Online-Lexikon, 3rd edn. Oldenbourg, Munich

Berenbach B, Borotto G (2006) Metrics for model driven requirements development In: Proceedings of the 28th international conference on software engineering (ICSE 2006), Shanghai, China. ACM, New York, pp 445-451

Bhat JM, Mayank G, Murthy SN (2006) Overcoming requirements engineering challenges: lessons from offshore outsourcing. IEEE Softw 23(5):38-44

Boos E, lesalnieks J, Keller F, Moczadlo $\mathrm{R}$ Rathgeb K, Rohlfes M, Schmidt C, Stimmer $J$ (2005) Leitfaden Offshoring. Bundesverband Informationswirtschaft, Telekommunikation und neue Medien e.V., Berlin

Brown AW (2000) Large-scale, componentbased development. Prentice-Hall, Upper Saddle River

Christiansen H (2007) Meeting the challenge of communication in offshore software development. In: Meyer B, Mathai J (eds) Software engineering approaches for offshore and outsourced development. First international conference, SEAFOOD 2007 Zurich. Lect notes comput sci, vol 4716. Springer, Heidelberg, pp 19-26

Coase RH (1937) The nature of the firm. Economica 4(16):386-405

Corriveau J-P (2007) Testable requirements for offshore outsourcing. In: Meyer $B$, Mathai J (eds) Software engineering approaches for offshore and outsourced development. First international conference, SEAFOOD 2007, Zurich. Lect notes comput sci, vol 4716. Springer, Heidelberg, pp $27-$ 43

Cusick J, Prasad A (2006) A practical management and engineering approach to offshore collaboration. IEEE Softw 23(5):2029

D'Souza DF, Wills AC (1999) Objects, components, and frameworks with UML: the catalysis approach. Addison-Wesley, Upper Saddle River

Davenport T (2004) What stays and what goes? Sourcing processes and jobs in the global economy. In: A CFO magazine symposium: offshore outsourcing - risks and rewards. Conclusions paper, The Metropolitan Club, New York, NY, 17 June 2004. CFO, New York

Davis AM (1993) Software requirements: objects, functions, and states. Prentice Hall, Englewood Cliffs

Dibbern J, Goles T, Hirschheim R, Jayatilaka B (2004) Information systems outsourcing: a survey and analysis of the literature. DATA BASE Adv Inf Syst 35(4):6-102

Dibbern J, Winkler J, Heinzl A (2008) Explaining variations in client extra costs between software projects offshored to India. MIS Q 32(2):333-366

Erber G, Sayed-Ahmed A (2005) Offshore outsourcing: a global shift in the present IT industry. Intereconomics 40(2):100-112

Gefen D, Wyss S, Lichtenstein Y (2008) Business familiarity as risk mitigation in soft- ware development outsourcing contracts. MIS Q 32(3):531-551

Gsell B, Overhage S, Turowski K (2008) Unzureichende Leistungsbeschreibung bei der Softwareentwicklung und die Rolle von Standardverträgen. In: Möllers T (ed) Standardisierung durch Markt und Recht. Nomos, Baden-Baden, pp 23-48

Hall A (1990) Seven myths of formal methods. IEEE Softw 7(5):11-19

Hansen HR, Neumann G (2009) Wirtschaftsinformatik 1: Grundlagen und Anwendung, 10 th edn. Lucius \& Lucius, Stuttgart

Heeks R, Krishna S, Nicholson B, Sahay S (2001) Synching or sinking: global software outsourcing relationships. IEEE Softw 18(2):54-60

Heindl M, Biffl S (2006) Risk management with enhanced tracing of requirements rationale in highly distributed projects. In: Proceedings of the 2006 international workshop on global software development for the practitioner, Shanghai, China. ACM, New York, pp 20-26

Hevner AR, March ST, Park J, Ram S (2004) Design science in information systems research. MIS Q 28(1):75-105

Hofstede G (1997) Lokales Denken, Globales Handeln: Kulturen, Zusammenarbeit und Management. Beck, Munich

IEEE (1998) IEEE recommended practice for software requirements specifications. IEEE standard, 830-1998. Institute of Electrical and Electronics Engineers, New York

King WR, Torkzadeh G (2008) Information systems offshoring: research status and issues. MIS O 32(2):205-225

Klein R, Scholl A (2004) Planung und Entscheidung: Konzepte, Modelle und Methoden einer modernen betriebswirtschaftlichen Entscheidungsanalyse. Vahlen, Munich

Kobitzsch W, Rombach D, Feldmann RL (2001) Outsourcing in India. IEEE Softw 18(2):7886

Kojima S, Kojima M (2007) Making IT offshoring work for the Japanese industries. In: Meyer B, Mathai J (eds) Software engineering approaches for offshore and outsourced development. First international conference, SEAFOOD 2007, Zurich. Lect notes comput sci, vol 4716. Springer, Heidelberg, pp 67-82

Krogstie J (1998) Integrating the understanding of quality in requirements specifications and conceptual modeling. ACM SIGSOFT Softw Eng Notes 23(1):86-91

Lacity M, Willcocks L (2003) IT sourcing reflections: lessons for customers and suppliers. WIRTSCHAFTSINFORMATIK 45(2): 115-125

Lamsweerde A van (2009) Requirements engineering: from system goals to UML models to software specifications. Wiley, Hoboken

Liskov BH, Berzins V (1986) An appraisal of programming specifications. In: Gehani N, McGettrickm AT (eds) Software specification techniques. Addison-Wesley, Wokingham, pp 3-24.

MacGregor E, Hsieh Y, Kruchten P (2005) Cultural patterns in software process mishaps: incidents in global projects. ACM SIGSOFT Softw Eng Notes 30(4):1-5

Moczadlo R (2002) Chancen und Risiken des Offshore-Development: Empirische Analyse der Erfahrungen. deutscher Unternehmen. http://www.competence-site.de. Accessed 2009-07-14

Morris C (1970) Foundations of the theory of signs. University of Chicago Press, Chicago

Nevo S, Wade M, Cook W (2006) An examination of the trade-off between internal and 
external IT capabilities. J Strateg Inf Syst 16(1):5-23

Overby S (2003) Offshore outsourcing the money: moving jobs overseas can be a much more expensive proposition than you may think. CIO 16(22):60-66

Overhage S (2006) Vereinheitlichte Spezifikation von Komponenten: Grundlagen, UnSCom Spezifikationsrahmen und Anwendung. Dissertation, Universität Augsburg, Augsburg

Overhage S, Thomas P (2005) WS-Specification: Ein Spezifikationsrahmen zur Beschreibung von Web-Services auf Basis des UDDI-Standards. In: Ferstl OK, Sinz EJ, Eckert S, Isselhorst T (eds) Wirtschaftsinformatik 2005: eeconomy, egovernment, esociety, Bamberg, Germany. Physica, Heidelberg, pp 1539-1558

Pruß M, Skroch O (2008) Kritische Defizite bei der Leistungsvereinbarung in SoftwareVerträgen: ein Bericht aus der Praxis. In: Möllers T (ed) Vielfalt und Einheit Wirtschaftliche und rechtliche Rahmenbedingungen von Standardbildung. Nomos, Baden-Baden, pp 263-278

Pryor B, Keane B (2004) Critical success factors in outsourcing. In: A CFO magazine symposium: offshore outsourcing - risks and rewards, The Metropolitan Club, New York, NY, June 17, 2004. CFO Publishing Corp New York, pp 11-13

Remus U, Wiener M (2009) Critical success factors for managing offshore software development projects. J Glob Inf Technolog Manag 12(1):6-29
Sakthivel S (2007) Managing risk in offshore systems development. Commun ACM 50(4):69-75

Scheffczyk J, Stutz C, Borghoff U, Siedersleben $J$ (2004) Formale Konsistenzsicherung in informellen Software-Spezifikationen. Inform Forsch Entwickl 19(1):17-29

Schienmann B (1997) Objektorientierter Fachentwurf: Ein terminologiebasierter Ansatz für die Konstruktion von Anwendungssystemen. Teubner, Stuttgart/ Leipzig

Setamanit S-O, Raffo D (2008) Identifying key success factors for globally distributed software projects using simulation: a case study. In: Wang Q, Pfahl D, Raffo D (eds) Making globally distributed software development a success story. International conference on software processes, ICSP 2008, Leipzig, Lect notes comput sci, vol 5007. Springer, Heidelberg, pp 320-332

Siakas KV, Maoutsidis D, Siakas E (2006) Trust facilitating good software outsourcing relationships. In: Richardson I, Runeson $\mathrm{P}$ Messnarz R (eds) Software process improvement. Proceedings of the 13th European conference, EuroSPI 2006, Joensuu, Finland. Lect notes comput sci, vol 4257 Springer, Heidelberg, pp 171-182

Steimle T (2007) Softwareentwicklung im Offshoring: Erfolgsfaktoren für die Praxis. Springer, Heidelberg

Takeda $\mathrm{H}$, Veerkamp $\mathrm{P}$, Tomiyama $\mathrm{T}$ Yoshikawa H (1990) Modeling design processes. Al Mag 11(4):37-48

Tsuji H, Sakurai A, Yoshida Ki, Tiwana A, Bush A (2007) Questionnaire-based risk as- sessment scheme for Japanese offshore software outsourcing. In: Meyer B, Mathai $J$ (eds) Software engineering approaches for offshore and outsourced development. First international conference, SEAFOOD 2007, Zurich. Lect notes comput sci, vol 4716. Springer, Heidelberg, pp 114-127

Vlaar PWL, Fenema PC van, Tiwari V (2008) Cocreating understanding and value in distributed work: how members of onsite and offshore vendor teams give make, demand and break sense. MIS O 32(2):227-255

Wada Y, Nakahigashi D, Tsuji H (2007) An evaluation method for offshore software development by structural equation modeling. In: Meyer B, Mathai J (eds) Software engineering approaches for offshore and outsourced development. First international conference, SEAFOOD 2007, Zurich, Lect notes comput sci, vol 4716 Springer, Heidelberg, $\mathrm{p}$ 114-127

Wehrmann A, Gull D (2006) Ein COCOMObasierter Ansatz zur Entscheidungsunterstützung beim Offshoring von Softwareentwicklungsprojekten. WIRTSCHAFTSINFORMATIK 48(6):407-417

Winkler J, Dibbern J, Heinzl A (2007) Der Einfluss kultureller Unterschiede beim IT-Offshoring: Ergebnisse aus Fallstudien zu deutsch-indischen Anwendungsentwicklungsprojekten. WIRTSCHAFTSINFORMATIK 49(2):95-103

Zangemeister C (1976) Nutzwertanalyse in der Systemtechnik - Eine Methodik zur multidimensionalen Bewertung und Auswahl von Projektalternativen, 4th edn. Wittemann, Munich 